\title{
Prospects of Wind Energy for Power Generation in University of Benin
}

\author{
H.O. Egware ${ }^{a, *}$, U.P. Onochie ${ }^{b}$, O.O. Ighodaro ${ }^{a}$ \\ ${ }^{a}$ Department of Mechanical Engineering, University of Benin, Benin City, Nigeria \\ ${ }^{b}$ National Centre for Energy and Environment, Energy Commission of Nigeria, University of Benin, Benin City, Nigeria
}

\begin{abstract}
Wind is a renewable energy resource by nature. It is clean, abundant, inexhaustible and environmentally friendly. Essentially, this study investigated the prospects of wind energy for power generation in University of Benin. Wind data from Jan $31^{\text {st }}-$ Dec $31^{\text {st }} 2013$ (at 10m height) was collected from National Centre for Energy and Environment, University of Benin. Accordingly, the annual and monthly wind speed and density are estimated using the 2- parameter Weibull probability density function. From the analysis, results obtained shows that the highest mean wind speed of $1.975 \mathrm{~m} / \mathrm{s}$ occurred in March and the lowest monthly mean speed of $0.977 \mathrm{~m} / \mathrm{s}$ occurred in November. Also, the annual mean wind speed is $1.496 \mathrm{~m} / \mathrm{s}$ while the annual mean power density based on Weibull distribution function is $2.692 \mathrm{~W} / \mathrm{m}^{2}$. Further results shows that the mean annual most probable wind speed and wind speed carrying maximum energy are $1.535 \mathrm{~m} / \mathrm{s}$ and $1.761 \mathrm{~m} / \mathrm{s}$ respectively. Thus, it is recommended that the institution can tap on the available wind power potential to augment its power supply.
\end{abstract}

Keywords: Prospects, wind energy potential, Weibull distribution, wind speed, wind power density.

\section{Introduction}

According to [1], renewable forms of energy in a wide range of environmental and engineering application had motivated a considerable research attention in recent times to meet the growing energy demand of the world's population and also to reduce the environmental impacts of the conventional energy resource that is almost unavoidable. Renewable energy resource from wind had been acknowledged to stand out as the most valuable and promising choice. By nature, the wind energy is clean, abundant, inexhaustible and environmentally friendly. The wind energy had also become one of the fastest growing renewable sources of energy in both developed and developing world due to its many advantages. For instance, [1] stated that renewable energy from wind is used in USA, Germany, Spain, Denmark, India and

${ }^{*}$ Corresponding author.

E-mail: okechukwu.egware@uniben.edu

(C) 2016 International Association for Sharing Knowledge and Sustainability

DOI: $10.5383 /$ ijtee.13.01.005
China. A total installed capacity of wind power had significantly increased globally, from 6100MW in 1996 to about 237, 699MW in 2011. [1], further listed some African countries such as Egypt, Morocco and Tunisia to have installed capacities of 550MW, 291MW and $114 \mathrm{MW}$ respectively. In Nigeria, there is a wind farm located in a small village of Rimi, $25 \mathrm{~km}$ south of Katsina City with a generating capacity of $10 \mathrm{MW}$ wind power plant, which is being built in the area and is almost ready for commissioning. The project, first envisioned by the Katsina State Government, gained full support from the federal government, through the Federal Ministry of Power (FMP), in 2007. The need to diversify Nigeria's energy needs, to boost electricity generation and have constant power supply, adding to the vast wind resources in the North of the country, were the main drivers for governmental support for this pioneer project in Nigeria. 
The increasing energy demand, the rapid depleting fossil fuel reserves and the environment problems associated with the use of fossil fuel have necessitated the development of alternative energy sources like wind energy for electricity generation in Nigeria. It is reported that the electricity production in Nigeria as of the end of 2010 is less than $4000 \mathrm{MW}$ due to fluctuations in the availability and maintenance of production sources, leading to a shortfall of supply [2]. The situation has not improved till now.

However, analyses of available wind data for selected cities have confirmed a high prospect of wind energy resources in Nigeria. Several studies on renewable sources of energy have also been performed. Worthy of mention here from these studies, however, is that the effective utilization of wind energy at a typical location requires sound knowledge of the wind characteristics and accurate wind data analysis [3]. For example, the choice of wind turbine design must be based on the average wind velocity at a selected wind turbine installation site [4]. Prior studies have also shown that the wind flow patterns are influenced by terrains, vegetables and water bodies.

It has been discovered in Benin-City that wind turbines are rarely used, and this has prompted the analysis of the wind data in University of Benin, Benin-city for future generation of electricity. According to [5] the few reported studies on wind speed in this part of the country were limited to wind speed distribution, while less attention was paid to the wind energy potential evaluation.

The need to reduce the effect of global warming posed by fossil fuel energy and poor power supply from Benin Electricity Distribution Commission (BEDC) in the University of Benin has led to the research on wind energy potential for electricity generation to serve as a complement to the existing ones. To determine the quantity of electric power available and harnessable from wind within the environment of University of Benin. Wind energy is a clean, renewable and environmental friendly. The data collected and analysed in wind speed analysis will be useful in designing and fabrication of a wind turbine for electricity generation. This study is centred on the analysis of wind data and wind energy potential for generation of electricity in University of Benin.

\section{Methodology}

\subsection{Data Collection}

The wind data used in this study were obtained from the National Centre for energy and environment, University of Benin, Nigeria. The geographical coordinates of the energy center where the wind speed data were captured is at latitude $06.32^{\circ} \mathrm{N}$, longitude $05.61^{\circ} \mathrm{E}, 77.8(\mathrm{~m})$ above sea level at a height of 10metres. Monthly wind data that spanned between $1^{\text {st }}$ January, 2013 to $31^{\text {st }}$
December, 2013 were obtained from the Centre. The mean wind speeds for each month were computed, which were used for the analysis.

However, using monthly mean wind speed, which is mostly available for most locations, can be used to study the seasonal changes in wind speed and facilitates wind data analysis. Prior studies have also shown that statistical methods such as the Weibull and Rayleigh distribution models can equally be used [6].

According to [7] and [8] and as stated in [2], the twoparameter Weibull probability distribution function is the most appropriate, accepted and recommended distribution function for wind speed data analysis. This is because it gives a better fit for measured monthly probability density distributions than other statistical functions [8]. In Weibull distribution, the variation in wind velocity is characterized by two parameter functions: the probability density function and the cumulative distribution.

\subsection{Frequency Distribution and Site Wind Speed Parameter}

The probability density function $f(V)$ indicates the probability of the wind at a given velocity $\mathrm{V}$, while the corresponding cumulative distribution function of the velocity $\mathrm{V}$ gives the probability that the wind velocity is equal to or lower than $\mathrm{V}$, or within a given wind speed range. The Weibull probability density function is defined as shown in Equation (1).

$$
f(v)=\frac{k}{c}\left(\frac{v}{c}\right)^{k-1} e^{-\left(\frac{v}{c}\right)^{k}}
$$

Where:

$\mathrm{F}(\mathrm{v})=$ the probability of observing wind speed $(\mathrm{V})$, $\mathrm{k}=$ dimensionless Weibull parameter and

$\mathrm{c}=$ the Weibull scale parameter $(\mathrm{m} / \mathrm{s})$.

The scale factor could be related to the mean wind speed through the shape factor, which determines the uniformity of the wind speed in a given site. The cumulative distribution $\mathrm{F}(\mathrm{v})$ is the integral of the probability density function, and it is expressed in Equation (2).

$$
F(v)=1-e^{-\left(\frac{v}{c}\right)^{k}}
$$

The monthly and annual values of Weibull parameters were calculated using standard deviation method. This method is useful where only the mean wind speed and standard deviation are available. In addition, it gives better results than graphical method and has relatively simple expressions when compared with other methods [7].

The parameter that indicates the variability or stability of the wind is the shape parameter $(\mathrm{k})$. There are various methods of determining Weibull $\mathrm{k}$ and c parameter. The scale factor and shape factor can be computed from Equations (3) and (4) used in [9]. 


$$
\begin{gathered}
k=\left(\frac{\sigma}{v_{m}}\right)^{-1.086} \\
C=\frac{v_{m}}{\Gamma\left(1+\frac{1}{k}\right)}
\end{gathered}
$$

Where, $\sigma$ is the standard deviation,

$\mathrm{V}_{\mathrm{m}}$ is the mean wind speed (in meter per second) and

$\Gamma(x)$ is the gamma function, which is defined as expressed in Equation (5) as stated in [10].

$$
\Gamma(x)=\int_{0}^{\infty} t^{x-1} e^{-t} d t
$$

$\mathrm{V}_{\mathrm{m}}$ and $\sigma$ can be computed applying Equations (6) and (7) as stated in [10].

$$
\begin{aligned}
& v_{m}=\frac{1}{n} \sum_{i=1}^{n} v_{i} \\
& \sigma=\left[\frac{1}{n} \sum_{i=1}^{n}\left(v_{i}-v_{m}\right)^{2}\right]^{0.5}
\end{aligned}
$$

In addition to the mean wind speed, the other two significant wind speeds for wind energy estimation are the most probable wind speed $\left(\mathrm{v}_{\mathrm{p}}\right)$ and the wind speed carrying maximum energy $\left(\mathrm{v}_{\mathrm{E}}\right)$. They can be expressed in Equations (8) and (9) respectively as used in [11].

$$
\begin{aligned}
& v_{p}=c\left(\frac{k-1}{k}\right)^{1 / k} \\
& v_{E}=c\left(\frac{k+2}{k}\right)^{1 / k}
\end{aligned}
$$

\subsection{Mean wind power density and energy density}

The mean wind power density can be estimated by using Equation (10).

$$
P_{D}=\frac{P(v)}{A}=\frac{1}{2} \rho v_{m}^{3}
$$

Where:

$\mathrm{P}(\mathrm{v})=$ the wind power (in watt)

$\mathrm{P}_{\mathrm{D}}=$ the wind power density (watt per square meter), $\rho=$ the air density at the site (assumed to be $1.225 \mathrm{~kg} / \mathrm{m}^{3}$ in this study) and

$\mathrm{A}=$ the swept area of the rotor blades (in square meter). Both the mean wind speed and power density are generally used to classify the wind energy resource (e.g.,
Pacific Northwest Laboratory (PNL) wind power classification scheme, [12]. However, the wind power density (wind power per unit area) based on the Weibull probability density function can be calculated using Equation (11) as stated in [13, 14].

$$
P_{D}=\frac{P(v)}{A}=\frac{1}{2} \rho c^{3} \Gamma\left(1+\frac{3}{k}\right)
$$

The mean Energy Density $\left(E_{D}\right)$ over a period of time $T$ is the product of the mean power density and the time $\mathrm{T}$, and it is expressed in Equation (12).

$$
E_{D}=\frac{1}{2} \rho c^{3} \Gamma T\left(1+\frac{3}{k}\right)
$$

\section{Result and Discussion}

\subsection{Wind speed frequency distribution}

The daily mean wind speeds measured various months used in the period considered are presented graphically as shown in Figure 1. The annual probability density frequency and cumulative distribution of wind speed for University of Benin was obtained using the Weibull distribution function. As expected the peak of the density function of this site skewed towards the higher values of the mean wind speed. The peak of the probability density function curve indicates the most frequent velocity as shown in Figure 2. It can be observed from the frequency distribution curve that the most probable mean wind speed within University of Benin is $2.0 \mathrm{~m} / \mathrm{s}$. (since it corresponds to the highest value of the probability function).

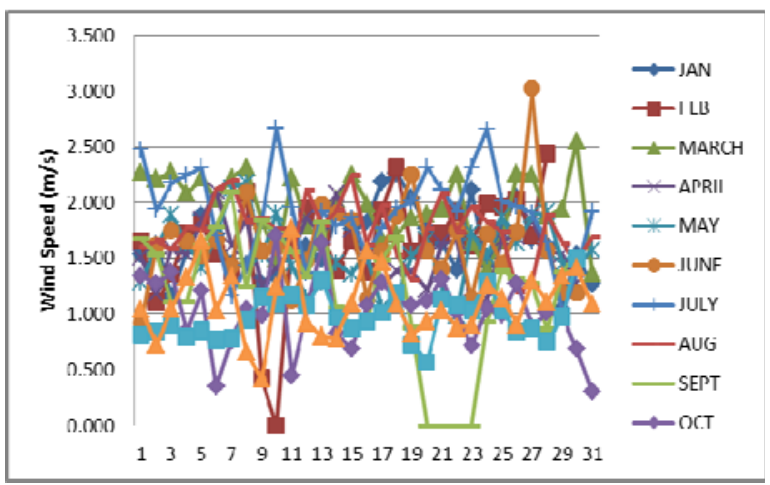

Figure 1: Daily mean wind speeds for the period considered. 
Okechukwu et al. / Int. J. of Thermal \& Environmental Engineering, 13 (2016) 23-28

Table 1: Characteristics speeds and mean power density in university of Benin at a height of 10m

\begin{tabular}{|l|l|l|l|l|l|l|c|c|}
\hline & $\begin{array}{l}\mathrm{V}_{\mathrm{M}} \\
(\mathrm{m} / \mathrm{s})\end{array}$ & $\sigma$ & $\kappa$ & $\mathrm{c}(\mathrm{m} / \mathrm{s})$ & $\mathrm{V}_{\mathrm{P}}(\mathrm{m} / \mathrm{s})$ & $\mathrm{V}_{\mathrm{E}}(\mathrm{m} / \mathrm{s})$ & $\mathrm{P}_{\mathrm{D}}\left(\mathrm{W} / \mathrm{m}^{2}\right)$ & $\mathrm{E}_{\mathrm{D}}\left(\mathrm{kWh} / \mathrm{m}^{2}\right)$ \\
\hline JAN & 1.648 & 0.297 & 6.439 & 1.769 & 1.723 & 1.845 & 3.004 & 2.162 \\
\hline FEB & 1.634 & 0.500 & 3.618 & 1.813 & 1.658 & 2.047 & 3.427 & 2.467 \\
\hline MAR & 1.975 & 0.300 & 7.736 & 2.101 & 2.064 & 2.164 & 5.045 & 3.632 \\
\hline APR & 1.555 & 0.265 & 6.837 & 1.664 & 1.626 & 1.728 & 2.501 & 1.800 \\
\hline MAY & 1.553 & 0.295 & 6.073 & 1.672 & 1.624 & 1.753 & 2.539 & 1.828 \\
\hline JUN & 1.623 & 0.404 & 4.523 & 1.778 & 1.683 & 1.928 & 3.108 & 2.237 \\
\hline JUL & 1.910 & 0.398 & 5.489 & 2.069 & 1.995 & 2.190 & 4.824 & 3.472 \\
\hline AUG & 1.756 & 0.260 & 7.972 & 1.865 & 1.834 & 1.918 & 3.532 & 2.542 \\
\hline SEP & 1.201 & 0.578 & 2.212 & 1.356 & 1.033 & 1.814 & 1.844 & 1.328 \\
\hline OCT & 1.016 & 0.324 & 3.463 & 1.129 & 1.024 & 1.288 & 0.839 & 0.604 \\
\hline NOV & 0.977 & 0.198 & 5.662 & 1.057 & 1.021 & 1.115 & 0.642 & 0.462 \\
\hline DEC & 1.102 & 0.301 & 4.095 & 1.214 & 1.134 & 1.338 & 1.003 & 0.723 \\
\hline ANN & 1.496 & 0.343 & 5.343 & 1.624 & 1.535 & 1.761 & 2.692 & 1.938 \\
\hline MAX & 1.975 & 0.578 & 7.972 & 2.101 & 2.064 & 2.190 & 5.045 & 3.632 \\
\hline MIN & 0.977 & 0.198 & 2.212 & 1.057 & 1.021 & 1.115 & 0.642 & 0.462 \\
\hline
\end{tabular}

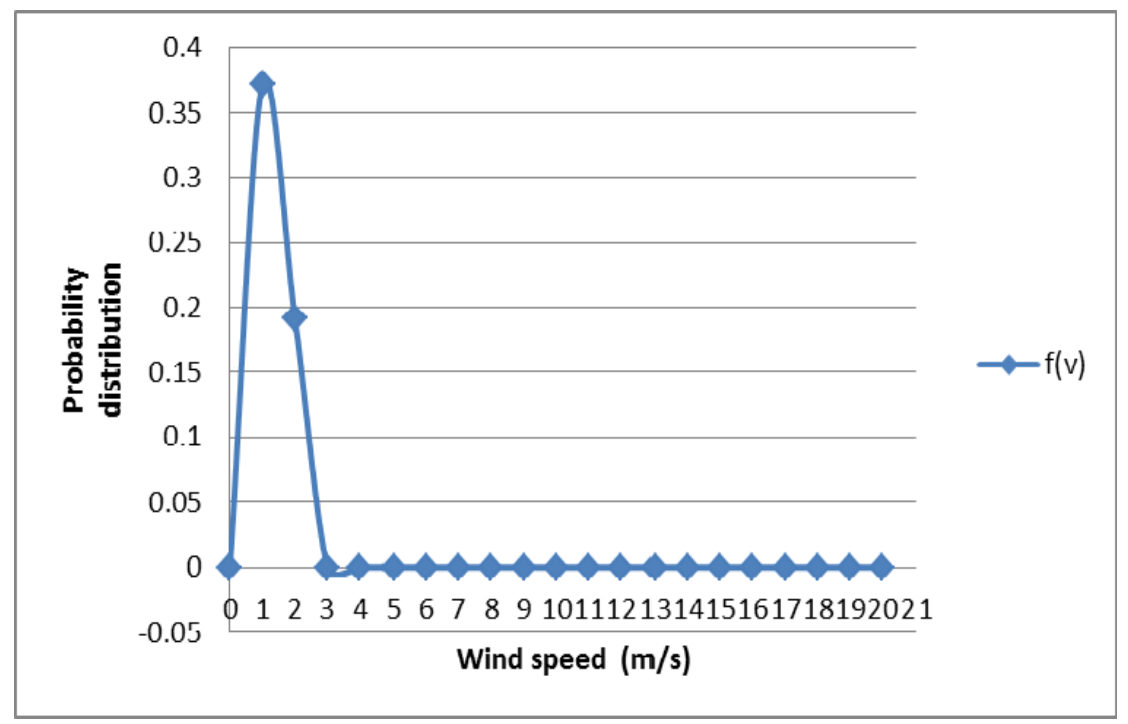

Figure 2: Annual probability distribution function 


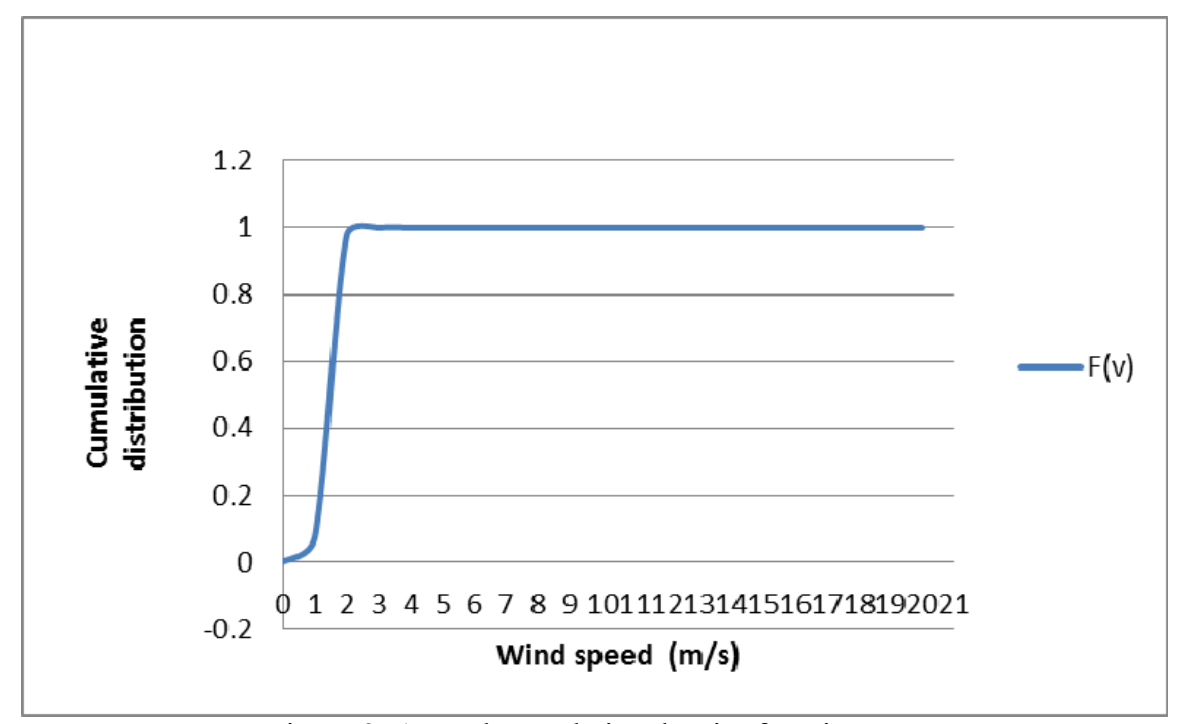

Figure 3: Annual cumulative density function

\subsection{Cut-in and cut-out speeds}

The cumulative probability distribution of the wind speed in this location shown in Figure 3 reveals that the cut in speed and cut out speed are between $2.4 \mathrm{~m} / \mathrm{s}$ and 3 $\mathrm{m} / \mathrm{s}$ respectively. [15] as reported in [3] stated a wind turbine system with a design cut in speed of $2.2 \mathrm{~m} / \mathrm{s}$ or more can be used in Nigeria for electricity generation. The frequency of more than $85 \%$ for the in speed as shown in Figure 3, which means wind turbines can be installed to generate electricity in this location.

\subsection{Mean wind speed and mean power density}

The different monthly mean speed characteristics $\left(\mathrm{V}_{\mathrm{M}}\right.$, $\mathrm{VP}$ and $\left.\mathrm{V}_{\mathrm{E}}\right)$, mean power density, $\left(\mathrm{P}_{\mathrm{D}}\right)$, mean energy $\operatorname{density}\left(\mathrm{E}_{\mathrm{D}}\right)$ and annual mean data obtained from their corresponding Equations at height of $10 \mathrm{~m}$ are presented in Table 1. As shown in Table 1, the monthly minimum and maximum mean wind speeds are $0.977 \mathrm{~m} / \mathrm{s}$ in November and $1.975 \mathrm{~m} / \mathrm{s}$ in March respectively. The monthly mean power density and energy density from $0,642 \mathrm{~W} / \mathrm{m}^{2}$ to $5.042 \mathrm{~W} / \mathrm{m}^{2}$ and $0.462 \mathrm{kWh} / \mathrm{m}^{2}$ to $3.632 \mathrm{kWh} / \mathrm{m}^{2}$ respectively.

The annual $\mathrm{v}_{\mathrm{p}}, \mathrm{V}_{\mathrm{E}}, \quad \mathrm{P}_{\mathrm{D}}$ and $\mathrm{E}_{\mathrm{D}}$ are $1.496 \mathrm{~m} / \mathrm{s}$, $1.535 \mathrm{~m} / \mathrm{s}, 1.761 \mathrm{~m} / \mathrm{s}, \quad 2.692 \mathrm{~W} / \mathrm{m}^{2}$ and $1.938 \mathrm{kWh} / \mathrm{m}^{2}$ respectively. The annual shape parameter for this site is 5.343 and for the scale parameter is $1.624 \mathrm{~m} / \mathrm{s}$. These parameters are important in the determination of wind turbine efficiency. The annual wind speed data obtained for this location can be used for the design of wind turbine. These parameters are useful for the design of a wind turbine for this site especially wind speed carrying maximum energy.

\section{Conclusion}

An analysis of the wind speed and wind power potential in university of Benn, Benin City, Nigeria was carried using Weibull distribution function. The annual mean speed of $1.496 \mathrm{~m} / \mathrm{s}$ at $10 \mathrm{~m}$ height was obtained for the period considered. The annual mean power density for the location is $2.692 \mathrm{~W} / \mathrm{m}^{2}$ while the annual mean energy density is $1.938 \mathrm{kWh} / \mathrm{m}^{2}$. The cut in speed obtained revealed that the location is viable for wind energy development. Therefore, it is necessary to recommend that the institution should utilize this knowledge to make plan for small scale wind turbine to supplement the current conventional electricity.

\section{Acknowledgments}

The authors are grateful to the National Centre for Energy and Environment, University of Benin for providing the data that was used for this research work.

\section{References}

[1] Global wind energy council: global wind report: annual market update. Http://www.gwec.net/webcite (2011). Acessed on $23 / 04 / 2014$.

[2] Fagbenle R.O.; Katende J.; Ajayi O.O; Okeniyi J.O (2011) "Assessment of wind energy potential of two sites in north east, Nigeria" Renew. Energy. 36, 1277-1293 for combustion and microbial sources J. Geophys.

[3] Obanor A.I, Agbonavbare G and Egware H.O (2014), Evaluation of Wind Energy potential for Electricity Generation at Three selected Locations in Nigeria, Journal of the Nigerian Association of Mathematical Physics, Vol. 27, pp 399 - 404. 
[4] Maras-Kaitis M.; Katnals V.; Karaliauskas A. (2008) "Wind power usage and prediction prospects in Lithuania. Renew. Sustain. Energy rev. 12, pp 256-277.

[5] Anyanwa E.E, Iwuagwu C.J. (1998). Wind characteristics and energy potential for Owerri, Nigeria. Renew. Energy. vol 6, page125-128

[6] Akpinar, E.K.; Akpinar, S.: (2005) "An assessment on seasonal analysis of wind energy characteristics and wind turbine characteristics. Energy Conversion and Management 46(1112), 1848-67.

[7] Jowder, Fal.; (2009) "'Wind power analysis and site matching of wind turbine generators in kingdom of Bahrain.' Applied energy 86, 538545.

[8] Akdag, S.A, Bagiorgas; H.S, Mihalakakou, G.; (2010) 'use of two-component weibull mixtures in the analysis of wind speed in the Eastern Mediterranean, Applied Energy 87(8), 2566-2573

[9] Lu L., Yang $\mathrm{H}$ and Burnet J (2002), Investigation on Wind Power Potential on Hong Kong Island - An Analysis of Wind Power and Turbine Characteristics, Renewable Energy 27, 1- 12 .
[10] Ouammi, A, Dagdougui, H, Sacile, R, Mimet, A: Monthly and seasonal assessment of wind energy characteristics at four monitored locations in Liguria region (Italy). Renew. Sustain. Energy Rev. 14, 1959-1968 (2010)

[11]Bagiorgas H.S, Assimakopoulos M.N, Theoharopoulos D, Matthopoulous D, Mihalakakou G.K (2007), Electricity Generation using Wind Energy Conversion Systems in the Areas of Western Greece, Energy Conversion and Management, 48, 1640 - 1655 .

[12]Llinca, A.; Mccarthy, E.; Chaumel, J.L.; Retiveau, J.L. (2003). "wind potential assessment',

[13] Celik, A.N., 2004. A statistical analysis of wind power density based on the Weibull and Rayleigh models at the southern region of Turkey. Renewable Energy 29(4), 593-604

[14] Oyedepo S.O. Muyiwa S. Adaramola Samuel S. Paul, "Analysis of wind speed data and wind energy potential in three selected locations in South-East Nigeria'.

[15] Ojusu J.O and Salawu R.I (1990), A Survey of Wind Energy Potential in Nigeria, Solar and Wind Technology, 7, 155 - 167. 